NASA Technical Memorandum 81508

\title{
ENGINE ENVIRONMENTAL EFFECTS \\ ON COMPOSITE BEHAVIOR
}

(NASA-TM-81508) ENGINE ENVTBOHHENTAL $20 \%$

EFPLCTS ON COMPOSITE BEHAVIOR (NASA) 20 CSCL 110

HC A 02/MF $\triangle 01$

$N 80-23370$

$\begin{array}{ll}\text { Unclas } \\ 20124 & 20116\end{array}$

C. C. Chamis and G. T. Smith

Lewis Research Center

Cleveland, Ohio

Prepared for the

Twenty-first Structures, Structural Dynamics and Materials Conference cosponsored by the AIAA, ASME, ASCE, and AHS

Seattle, Washington, May $12-14,1980$

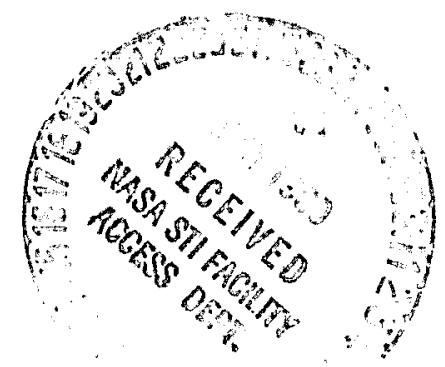




\section{ENGINE ENVIRONMENTAL EFFECTS ON COMPOSITE BEHAVIOR}

by C. C. Chamis and G. T. Smith

National Aeronautics and Space Adninistration

Lewis Research Center

Cleveland, onio 44135

\section{ABSTRACT}

The Lewis Research center has conducted a series of programs intended to investigate and develop the application of composite materia:s to turbojet engines. A siqnificant part of that effort was directed to establishing the impact resistance and defect growth characteristics of composite materials over the wide range of environmental conditions found in commercial turbojet engine operations. Both analytical and empirical efforts are involved. This paper summarizes the experimental programs and the analytical methodology development as well as an evaluation program for the use of composite raterials as fan exit guide vanes.

\section{INTROOUCTION}

The development of implementation technology for more durable, weight efficient, cost effective engine structures is the objective of a recently expanded engine structures research program at the NASA Lewis Research Center. Coordinated programs involving in-house, university and industry activities are being initiated to address difficult engine development problems and to effectively incorporate new analys is techniques and materials developments into currently evolving engine systems. These programs include a substantial efforc to exploit the unique mechanical and manufacturing characteristics of newly developed composite material systems. Evaluations of graphite/epoxy composites and hybrid composites for fan blades, tan exit guide vanes (FEGVS), 
engine frames, nacelle components, engine ducts and other relatively low temperature structures are being or have been conducted.

A major part in these programs is the evaluation of the engine environmental effects (moisture and temperature) on composite mater,al mechanical behavior. The objective of this paper is to summarize research being conducted and results obtained dealing with engine environmental effects on impact resistance, defect growth and fracture of compsites, and the fatigue resistance of composite FEGVS.

\section{HIGH VELOCITY IMPACT}

The experimental program on impact resistance has been conducted by Genera) Electric under NASA contract NAS3-21017. It involves evaluation of six composite systems, seven environmental conditions and three test conditions. The composite systems consist of graphite-fiber/epoxy (T300/PR288) as the base line material, two graphite-S-glass/epoxy intraply hybrids (different fiber types within the same ply), one graphite-S-glass/polyimide, and two superhybrids (combination of metallic foils, and resin and metal matrix fiber composites adhesively bonded together). The intraply graphite-S-glass/epoxy systems used PR288 and SP313 as the intrix mater:als. The polyimide selected was NR150r:2 and the superhybrids used PR288 and SP313 epoxy as matrix materials. The test conditions consisted of $70^{\circ} \mathrm{F}$ dry, wet, and wet spike; and $250^{\circ} \mathrm{F}$ dry, wet and wet spike. Mechanical property test data included static flex, shortbeam-shear, and high velocity impact strengths. The "wet spike" specimens were subjected to an abrupt temperature excursion from room temperature to $300^{\circ} \mathrm{F}$ followed by cooling to test temperature. The cooling rate was slow relative to the hearing rate but was sufficiently rapid to prevent a loss of moisture from the test specimens. 
The PRaB8 epoxy was selected for its ease of processing which is advantageous in making complex engine components such as fan blades. The SP313 epoxy was chosen because it is the most commonly used epoxy in structural applications and has about $100^{\circ} \mathrm{F}$ higher temperature capability than PR?88. The NRIbUA? polyimide was selected for its potential use in the hotter parts of the engine (parts operating at temperatures from $300^{\circ} \mathrm{F}$ to $5100^{\circ} \mathrm{F}$. The two superhybrids were selected for their unique material property characteristics which provide high impact resistance combined with high strength, high stiffness and moisture resistance. Both unidirectional and angleply specimens were tested. Unidirectional specimens were tested for moisture absorption and moisture-temperature strength degradation. Short beam (interlaminar) shear and three-point-bend specimens were tested for strength degradation. Degradation of impact resistance due to moisture and temperature was evaluated using angleply wedge specimens with multiples of $0 / \pm 35$ degree plies symmetric about the mid-plane.

Experimental data on moisture absorption in composites made from the three different resin systems are shown in figure 1 . The saturation moisiure (curve leveling off) is about 2 percent for the composites with the PR288 resin, about 1.2 percent with the SP313 resin and about 0.8 percent for the composites with the NR150A2 poiyimide. As expected, the 90 degree specimens absorbed more moisture than the 0 degree specimens due to greater interfacial surface exposure (more fiber ends at the surface). A?though the data are not shown in figure 1 , the superhybrid specimens absorbed no measureable moisture. Experimental data on the moisture-temperature effects (strength retention) of longitudinal shear specimens are shown in figure $2(a)$ in bar chart form. The composite with PR228 resin has the lowest strength retention for the combined wet and thermal conditions $\left(250^{\circ} \mathrm{F}\right.$ wet or wet spike) which is about 25 percent of the room temperature dry strength. The corresponding 
strength retention was about 40 percent for the composite made with SP3L 3 and about 70 percent for the composite with NR15UA2.

Experimental data for moisture-temperature effect on longitudinal flexural strength are shown in figure $2(b)$. The longitudinal flexural strength retention for the three resin composite systems at the $250^{\circ} \mathrm{F}$ wet and $250^{\circ} \mathrm{F}$ wet spike conditions (severest cases) are as follows: PR284 composites about 30 percent of the $70^{\circ} \mathrm{F}$ (room temperature dry), about 70 percent for the SP313 composites and nearly 100 percent for the NRI5OA2 composites.

Experimental data for transverse interlaminar (short-beam) shear strength are shown in figure $2(c)$ and for transverse flexural strength in figlre $2(d)$. The strength retention of the transverse interlaminar shear strength at the $150^{\circ} \mathrm{F}$ wet or $250^{\circ} \mathrm{F}$ wet spike condition is about 30 percent of the $70^{\circ} \mathrm{F}$ ary strength for the PRZZ8 and SP313 composites, and about 45 percent for the NR15OA2 composites. The corresponding transverse flexural strength retention is about 30 percent for the PR288 and SP313 composites and about 70 percent for the NRISOA? composites.

Taken collectively, the data in figure 2 show that the environmental conditions of $250^{\circ} \mathrm{F}$ wet or wet spike reduce substantially (as much as 75 percent) the shear and flexural'strengths in epoxy composites while the corresponding reduction in the polyimide composites is only 30 percent, except for transverse intralaminar shear which is reduced about 60 percent. In addition, these data provide material strength characteristics which can be used in conjunction with the high velocity impact analysis to assess the environmental effects on impact resistance as will be described later.

The high velocity impact test conditions and wedge specimen configuration are summarized on figure 3 . The experimental data for environmental effects on impact resistance, as measured by area delamination (determined by C-scan 
measurements) are summarized in figure 4 for the impact conditions of 100 $\mathrm{ft} / \mathrm{sec}$ and $y 00 \mathrm{ft} / \mathrm{sec}$. The principal points estaklished by the data of figure 4 are: (1) the environmental and impact condition's investigated had an insignificant effect on the impact resistance of superhybrids, a minor effect on the polyimide composites and a severe effect on the epoxy composites; (2) the $250^{\circ} \mathrm{F}$ wet spike environmental impact conditions generally caused the greatest delamination in the epoxy composites; and (3) the $900 \mathrm{ft} / \mathrm{sec}$ velocity impacts caused much more delamination tran the $100 \mathrm{ft} / \mathrm{sec}$ velocity imparts, especially in the epoxy composites.

Pertinent information about the high velocity impact analys is (composite mechanics references $1,2,3$ and $\Lambda .3$ TRAN reference 4 ) is summarized in figure 5. Results obtained from this analysis are shown graphically in figure $b$ for stresses near the impact point on the impact surface, and in figure 7 for stresses on the back surface. These stresses are for the PR288/T300 wedge specimen. They are typical of wedge specimen results from the analysis of other composite systems (including superhybrids). All systems have approximately the same stresses early (first 100 microseconds ( $\mu \mathrm{sec})$ ) in the impact event. The analysis performed was linear. This linearity implies that the stresses shown in figures 6 and 7 are correct only prior to the onset of initial damage. This applies only early in the impact event and is the condition used for assessing the effects of moisture-temperature condition on impact resistance.

The inplane predicted stresses for initial damage for tour test conditions $70^{\circ} \mathrm{F}$ dry, $250^{\circ} \mathrm{F}$ dry, $250^{\circ} \mathrm{F}$ wet and $250^{\circ} \mathrm{F}$ wet spike were determined (using the composite mechanics methods, references 1,2 and 3.) The results are shown as straight horizontal lines in figures 6 and 7 . The through-the-thickness shear stress (not shown on figures $\vec{b}$ and 7 ) is about $10 \mathrm{ksi}$ compared to the shortbeam shear strength of about $15 \mathrm{ksi}$ for $70^{\circ} \mathrm{F}$ dry and $4 \mathrm{ksi}$ for $250^{\circ} \mathrm{F}$ wet and 
wet spike conditions. The inplane and through-the-thickness predicted stresses for failure indicate that damage will occur very early in the impact event and will be at considerably lower transverse and interlaminar shear stresses (about 30 percent) for the $250^{\circ} \mathrm{F}$ wet compared to the $10^{\circ} \mathrm{F}$ ury case. However, the superhybrids will sustain only localized damage in the form of indentation since the moisture-temperature test condition does not seriously degrade the superhybrid mechanical properties. One conclusion from the foregoing discussion is that the impact damage of fiber-resin composites in moisture-temperature environments can be assessed using available finite element analysis methods and composite mechanics.

\section{DEFECT GROWTH AND FRACTURE}

The experimental program for environmental effects on defect growth in composites is being conducted by Boeing Aerospace under NASA contract NAS3-20405. This program consists of the evaluation of (1) graphite-fiber/ epoxy angleplied laminates with three different laminate configurations; (2) four environmental conditions; (3) three defect types; and (4) three test loading conditions. The graphite/epoxy angleplied laminates are made from T300/934 as follows: (1) baseline laminate, $L_{1},[0 / 45-45 / 0 / 90 / 90 / 0 /-45 / 45 / 0]_{5}$; (2) pressure vessel type laminate, $\left.L_{2}, L\left(0_{3} / \pm 80_{2}\right)\right\rfloor_{5}$; and 3$)$ fan blade type laminate, $L_{3},[0 / 30 / 0 \mathrm{~S} /-30 / 0 / 30 / 0 \mathrm{~S} /-30 / 0]_{S}$ where the $0^{S}$ denotes $S-g$ lass/ epoxy plies. The environmental conditions investigated consist of: (1) room temperature dry and wet; and (2) $300^{\circ} \mathrm{F}-d r y$, wet and wet spike. The defect types are: (1) full and half penetration holes; (2) full and half penetration slits; and (3) embedded delaminations. The test conditions are: (1) monotonic load to fracture (static); (2) cyclic load to fracture; and (3) cyclic load to fracture following preloading to 90 percent of the monotonic fracture load. Visual and ultrasonic methods and continuous crack opening displacement 
instrumenation are used to monitor the defect growth. The room temperature dry tatique and fracture data of this program have been previously reported in Netall in reference b. Testing of the high moisture, high temperature specimens is currently in progress. The effect of applying preloads up to yo pero cent of the monotonic fracture load on the subsequent moisture absorption of the angleply composite specimens is shown in figure 8. Aftar eight weeks of exposure consisting of complete immersion in $180^{\circ} \mathrm{F}$ water, the percentage weight gain for the preloaded specimens showed no definite correlation with preload level for any of the three laminate configurations investigated.

The environmental and preload effects on the fracture of the baseline laminate with slits are shown in figure $y$. The results are essentially the same for the other two laminates. Also, these results are about the same for all three laminates with equal size holes, and may be considered to be representative of laminates with equal size, full penetration defects. It can be seen in figure $y$ that: (1) elevated temperature $\left(300^{\circ} \mathrm{F}\right)$, moisture $(1.9$ percent by weight) and preload (about 90 percent of fracture) have no effect on the fracture load of laminates with defects and (2) elevated temperature decreases the fracture load (about 30 percent) of specimens without defects. The conclusion, therefore, is that moisture-temperature environments investigated have no significant effect on the fracture load of graphite/epoxy composites with defects.

A concurrent LERC in-house research effort is directed towards the development of the methodology required to predict the defect growth and propagation to fracture in composite structures subjected to environmental and mechanical loads. The objective of this in-house program is the development of an integrated computer program which is presently identified as CODSTRAN (COmposite DUrability STRuctural ANalysis). The composition and scope of CODSTRAN is illustrated schematically in figure 10 and its iritial form is described in 
some detall in reference 0 . CuUSIKAN was used to andyze specinens tested and data generated under the soeing contract.

Typical results obtained using coustkair are illustrated in figure 11. The predicted progressive damage in the slotted laminate is comparea with all ule trasonic b-scan record. It can be seen from figure 11 that coustkair predicts a damage pattern which is in essential agreement with that shown by the experimental l-scan data. This comparison is based on the $70^{\circ} \mathrm{F}$ ary specimen test Jata and the corresponding $10^{\circ} \mathrm{r}$ dry, composite mechanical property data for the CODSIRAN program. Modification of the CUOSTRAN program by utilizati.. of the matrix and tiber mechanical property data for the high temperature, wet conditions is currently being accomplished and comparisons such as presented in figure 11 are planned to be made for the $300^{\circ} \mathrm{F}$, fully wet conditions.

FATIGUE OF FAN EXIT GUIUE VANES

The engine environmental effects on composite fan exit guide vanes ( 1 tobs) were investigated by Pratt and Whitney under NASA contract NAS3-21037. The engine application for the rtovs is illustrated in figure 12 which shows conposite FEGVs installed in a JT9U engine. Four different designs were evaluated involving two different fabrication procedures, pultrusion and handlay-up (references 7 and 8 ).

All four designs contained a high modulus graphite fiber core (Fortafil 5A) to provide adequate bending stiffness. Each fabrication process involved one all-graphite fiber vane design and one graphite core-fiberglass shell design. The pultrusion all-graphite vane used high modulus, $48 \mathrm{msi}$, fortaf il $5 \mathrm{~A}$ fibers for both the core and shell. The hand-lay-up all-graphite vane used the high modulus fortafil 5A fibers for the core and a lower modulus, $32 \mathrm{~ms} i$, AS-2 graphite fiber shell. The shell for the pultrudeu core was made from 6581 style S-glass cloth and the hand-lay-up vane shell was made from S-c 
ylass roving. The laminate configuration for the glass shells consisted of \pm 45 aegree plies. For the gruphite shells the configuration was $\$ 36$ degrees for pultrusion vane and +30 degrees for the hardalayoup vane.

The plovs were tested in simulated engine environments of moisture, temo perature and tatigue loading in addition to other mechanical tests required to quality the feovs for a tlight readiness test program. The results from the environmental fatigue testing effort are summarized in tigure ls. The tatigue data obtained exceed the operational engine strain fatigue design requirenent (about 700 we for $10^{7}$ cycles) by at least a factor of two. It can be seen in figure 13 that all fatigue tailures, except one, occurred at strain levels about three times the design requirement. Also these failures occurrea af ter several repetitions of $10^{7}$ cycles at lower strain levels. The data also show that the environmental conditions imposed $\left(0.8\right.$ percent moisture and $140^{\circ} \mathrm{F}$ temperature) had no discernible adverse effect on the fatigwe life of the FEGVs. The conclusion, therefore, is that composite FEGVs can be designed and fabricated to meet the anticipated engine operation environmental conditions.

\section{CONCLUSIONS}

The effects of engine environmental conditions of saturation moisture, and elevated temperature $\left(250^{\circ} \mathrm{F}\right.$ and $\left.300^{\circ} \mathrm{F}\right)$ on composite structural performance were investigated in several programs conducted by the NASA Lewis Kesearch center. These programs were concerned with the effects on mechanical properties determined by flexural type specimens, impact resistance of angleply wedge specimens, defect growth and fracture of angle ply flat specimens, and fatigue resistance of $f$ an exit guide vanes (FEGVs). Important conclusions from these programs are the following:

1. The moisture absorbed in fiber composites depends on the resin systems, 
and amount of tiber ends exposed. bpoxy resin composites absorbed the most moisture (about \& percent by weight) while polyimide resin composites absorbeo abeat 4.8 percent and superhybrid composites absorlat no moisture. 2. Both high moisture (saturation) and elevated temperature (250 $0^{\circ}$ ) conaio tions have severe effects on the texural and interlaminar shear properties of unidirectional composites. Strength degradation ranges trom about 30 percent for the polyimide conposites to 70 percent for those made from the processible epoxy (PR288). The $250^{\circ} \mathrm{F}$ wet environment was the most severe condition. 3. The environmental and impact conditions (900 ft/sec., 1 in diameter 0.302 gelatin bal1, 25 degree ine idence angle) produced insignificant damage to the superhybrid specimens (measured by delaminated area) and minor damage to the polyimide composites but severe damage to the epoxy composites. The $250^{\circ} \mathrm{F}$ wet spike impact condition caused the greatest delamination in the epoxy composites.

4. The impact damage to fiber composites in moisture-temperature environments can be assessed using available finite elenent analysis methods (such as NASTRAN) and composite mechanics analysis. The stress magnitudes near the impact region are very high relative to material allowables at, early times of the impact event (about the first $100 \mu$ seconds) and will induce significant damace in the resin composites. During this time interval, the stress magnitudes do not depend on the environmental conditions. However, the material allowables and the corresponding stresses at which initial damage occurs will depend on the environmental conditions, with the $250^{\circ} \mathrm{F}$ wet condition sustaining initial damage at lowest stress levels.

5. Preload, 1.9 percent moisture and $300^{\circ} \mathrm{F}$ temperature environmental conditions had no effect on the fracture load of composites with slit type defects. CODSTRA (an integrated computer program for Composite Uurabiity STRuctural ANal is), predicts defect growth which is in reasonably good 
agreement with ultrasonic loge an records for the $70^{\circ}$ ary test conditions and will be utilized for similar preditions at ligh moisture, high temperature conditions.

b. Engine operation environmental condit ons of 0.8 percent moisture and $140^{\circ} \mathrm{F}$ temperature had no discernible effect on the fatigue resistance of conm posite tan exit guide vanes (FtgVs), and composite ftgVs can be designed to exceed engine operational requirements.

\section{REFERENICES}

1. Chamis, l. C., "Lomputer Code for the Analysis of Multilayered Fiber Composites-User's Manual," NASA TN U-7013, 1971.

2. Chamis, L. C., Lark, K. F. and Sinclair, J. H., "Integrated Theory cor Predicting the Hydrotherm1-mechanical Response of Advanced Composite Structura! Components;" NASA TM-73812; 1977. AlSO ASTM-STP-658; $497 \underline{8}$; pp. $160-192$.

3. Chamis, C. C., "Prediction of Fiber Composite Mechanical Behavior Made Simple," NASA TM-81404, 1980.

4. McCormick, C. W., "NASTRAN User's Manual (Level 15)," NASA SP 222(01), 1972,

5. Porter, T. R, "Evaluation of Flawed Composites Structural Components Under Static and Cyclic Loading, Boeing Aerospace Co., Seattle, Wash., Feb. 1979. (NASA CR-135403).

6. Chamis, C. C. and Smith, G. T., "COUSTRAN: Composite Durability Structural Analysis," NASA TM-79070, 1978.

7. Smith, G. T., "Application of Composite Materials to Turbofan Engine Fan Exit Guide Vanes," NASA TM-81432, 1980.

8. Blecherman, S. S., "Design, Durabiliy, and Low-Cost Processing Technology for Composite Fan Exit Guide Vanes," Pratt a Whitney Aircraft Group, East Hartford, (T, NASA CR-159677, Aug. 1979. (PWA-5570-37). 


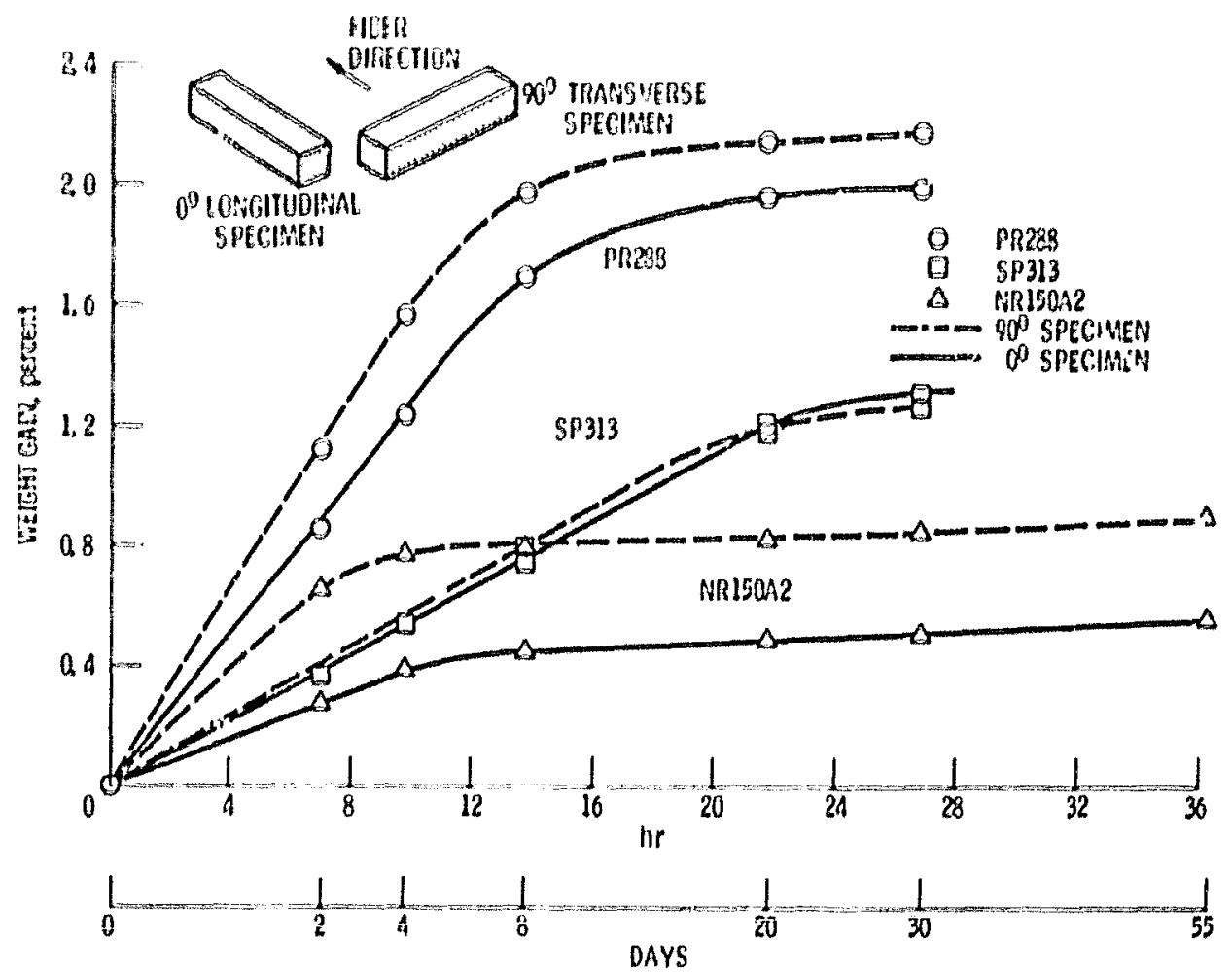

Figure 1. - Moisture absorption, $S$ aglass flexural specimons, conditions $180^{\circ}: 197$ percont R. H.
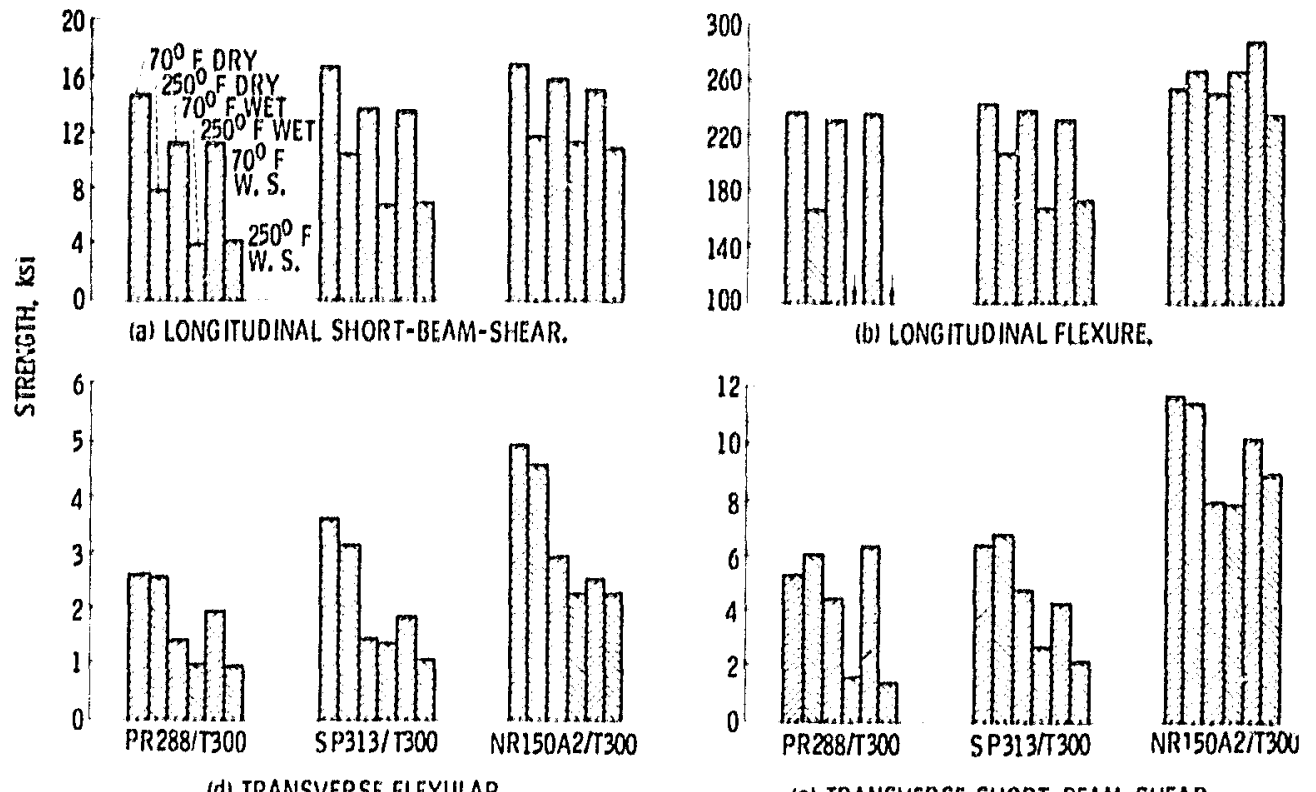

Figure 2. - Moisture/temperalure elfecls on flexural and shear strengths of resin/ 300 unldirectional compositos. 


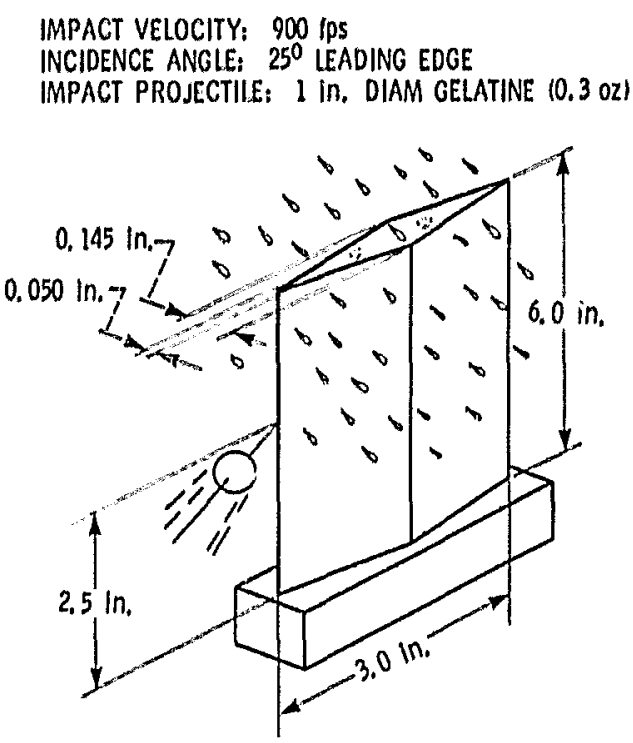

Figure 3. - Impact test conditions.

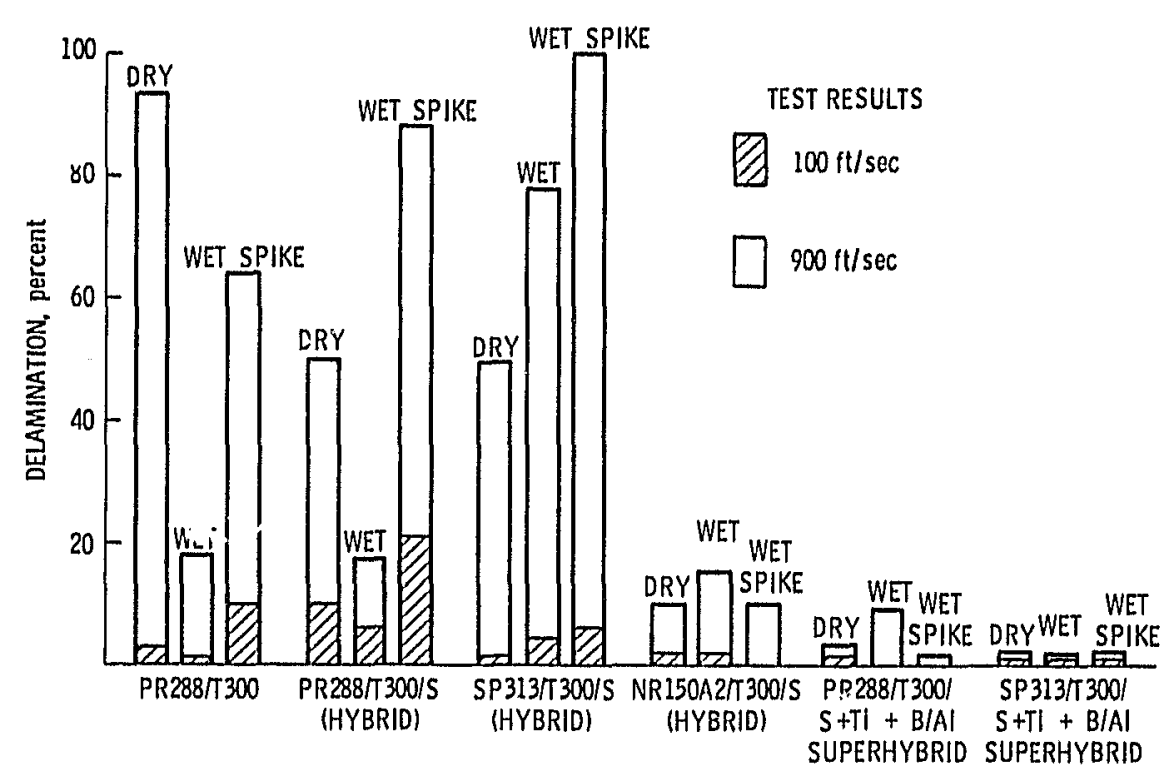

Flgure 4. - Damage comparison for $250^{\circ} \mathrm{F}$ environmental specimens. 


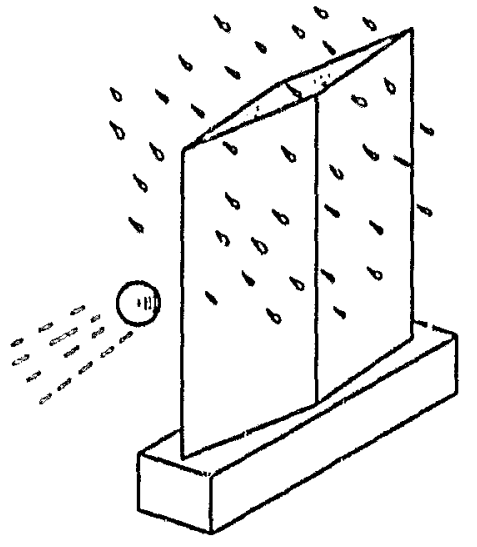

FINITE LLEMENT MODEL.

325 NODES; 1872 DEGREES OF FREEDOM 288 QUADRILATERAL. PLATE ELEMENTS

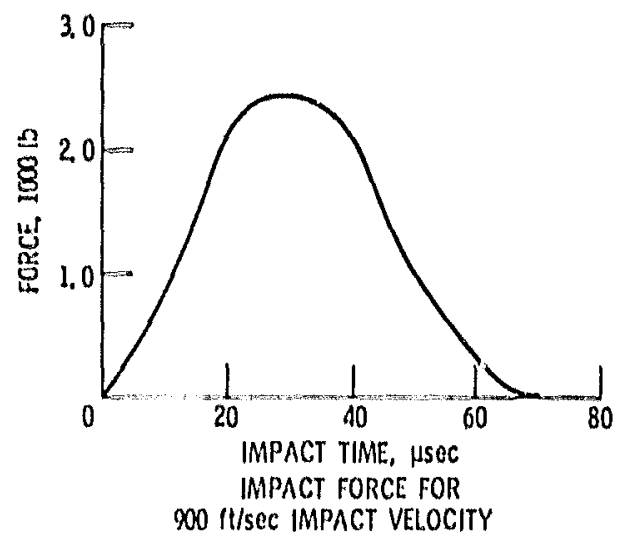

Figure 5. - Impact finite olement analysis, NASTRAN diract time response.

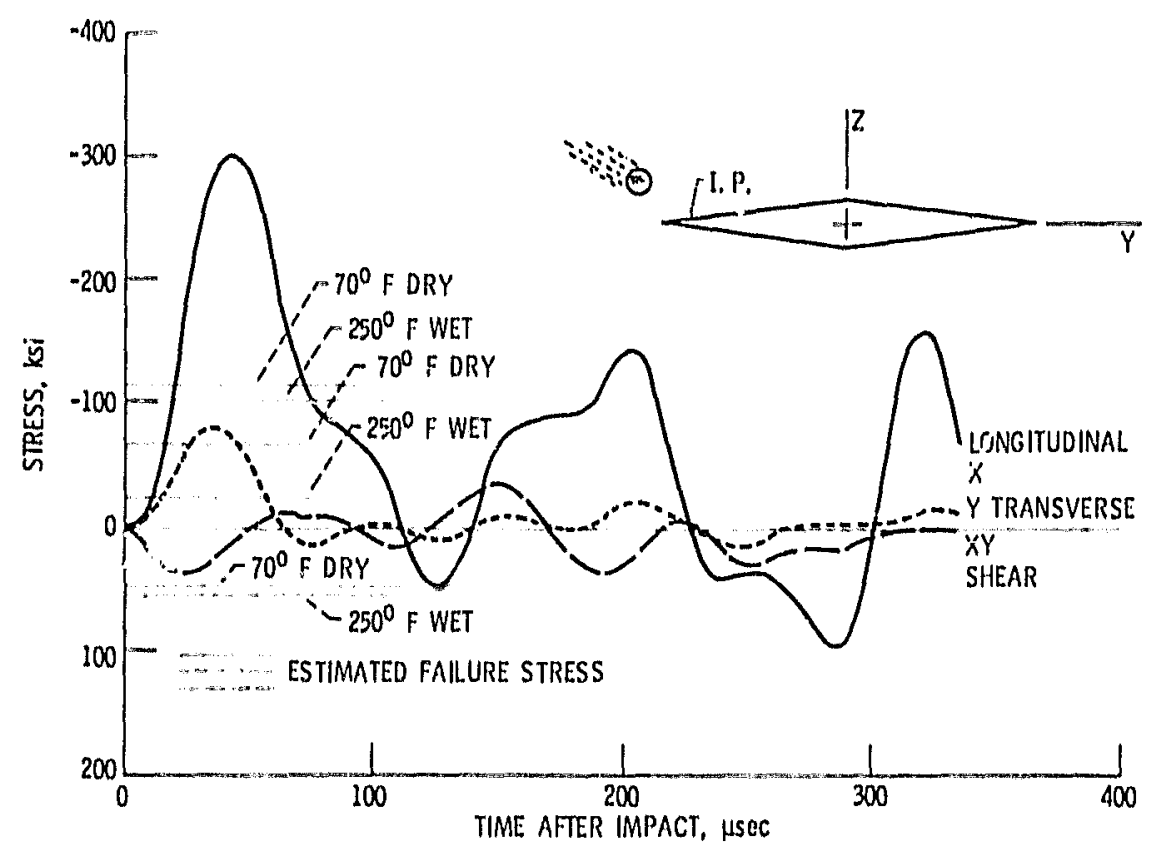

Figure 6. - Strosses near Impact poinl, impact surface. 
BACK SURFACE

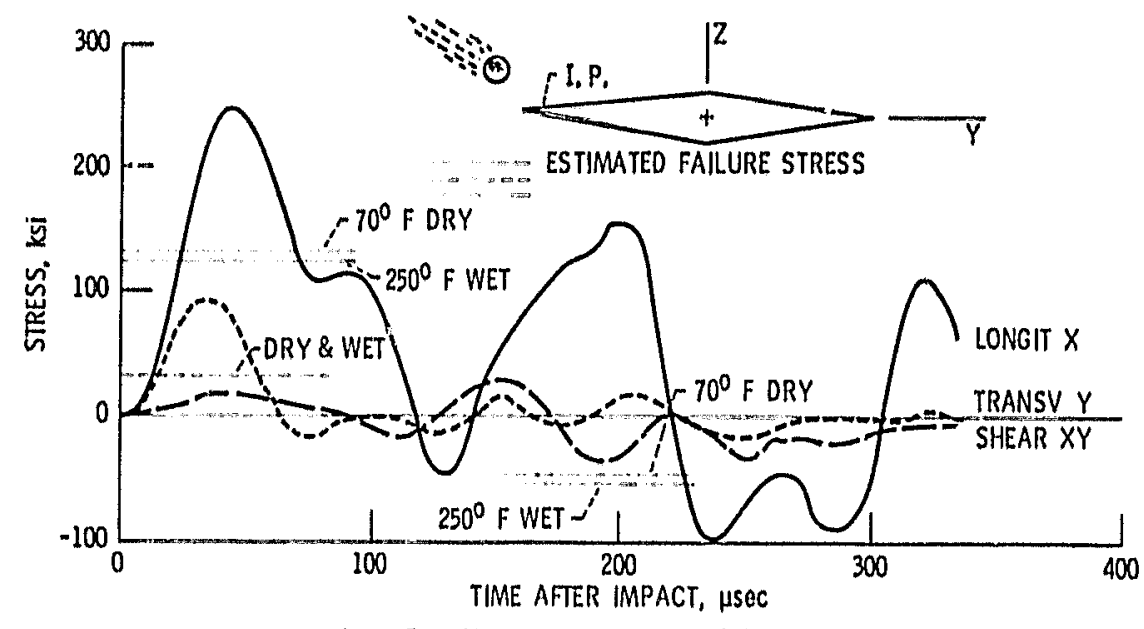

Flgure 7. - Stresses near impact polnt, back surface.

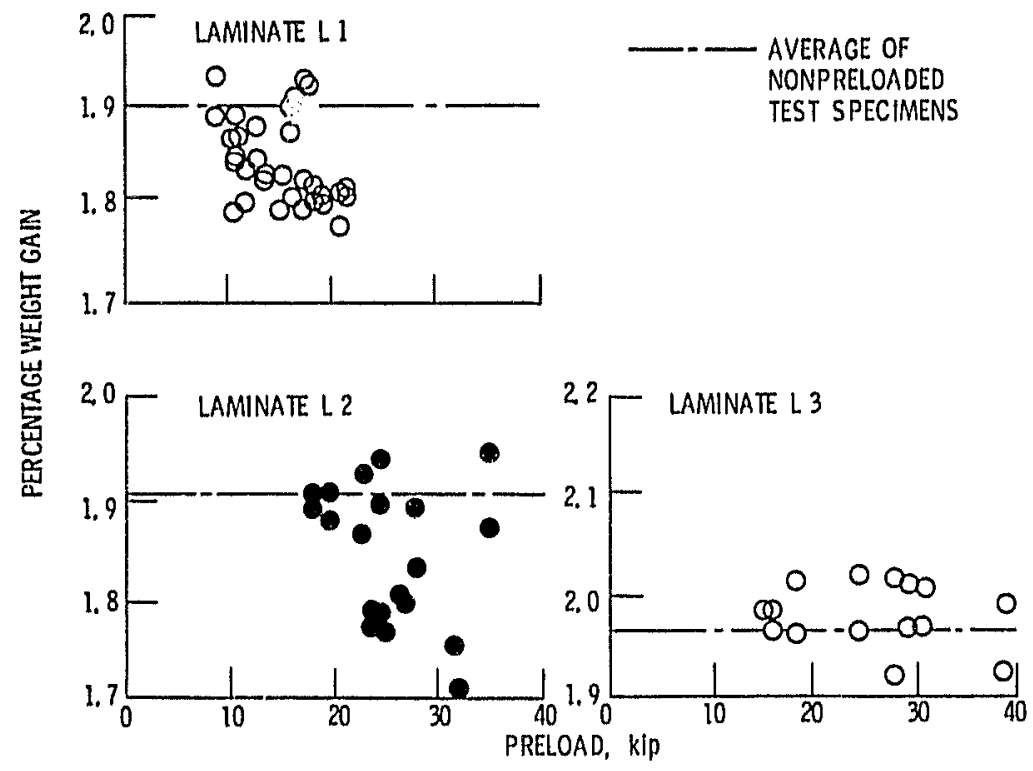

Figure 8. - Influence of preload on weight gain after elght weaks of exposure. 


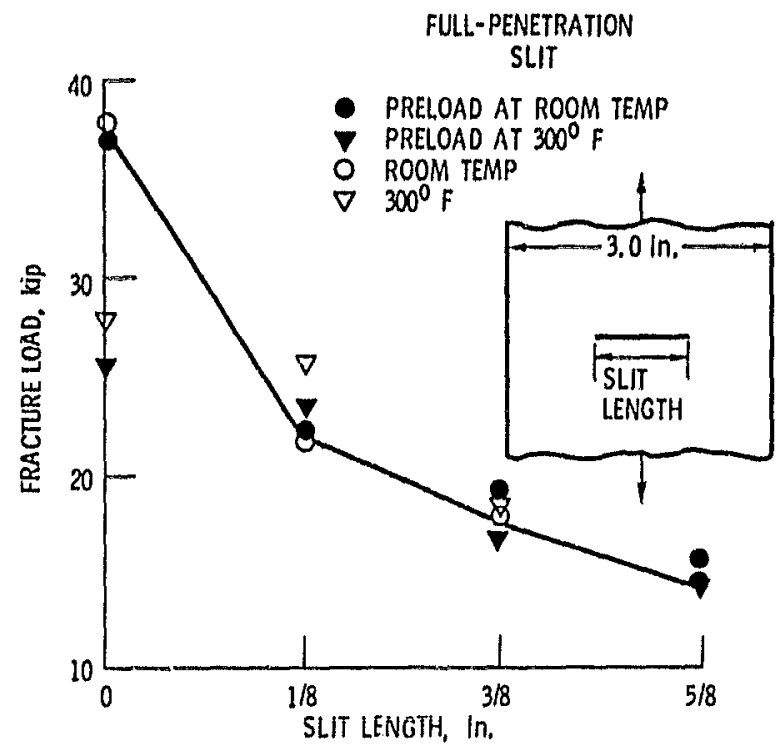

Flgure 9. - Slit specimen static fracture data for laminate L..

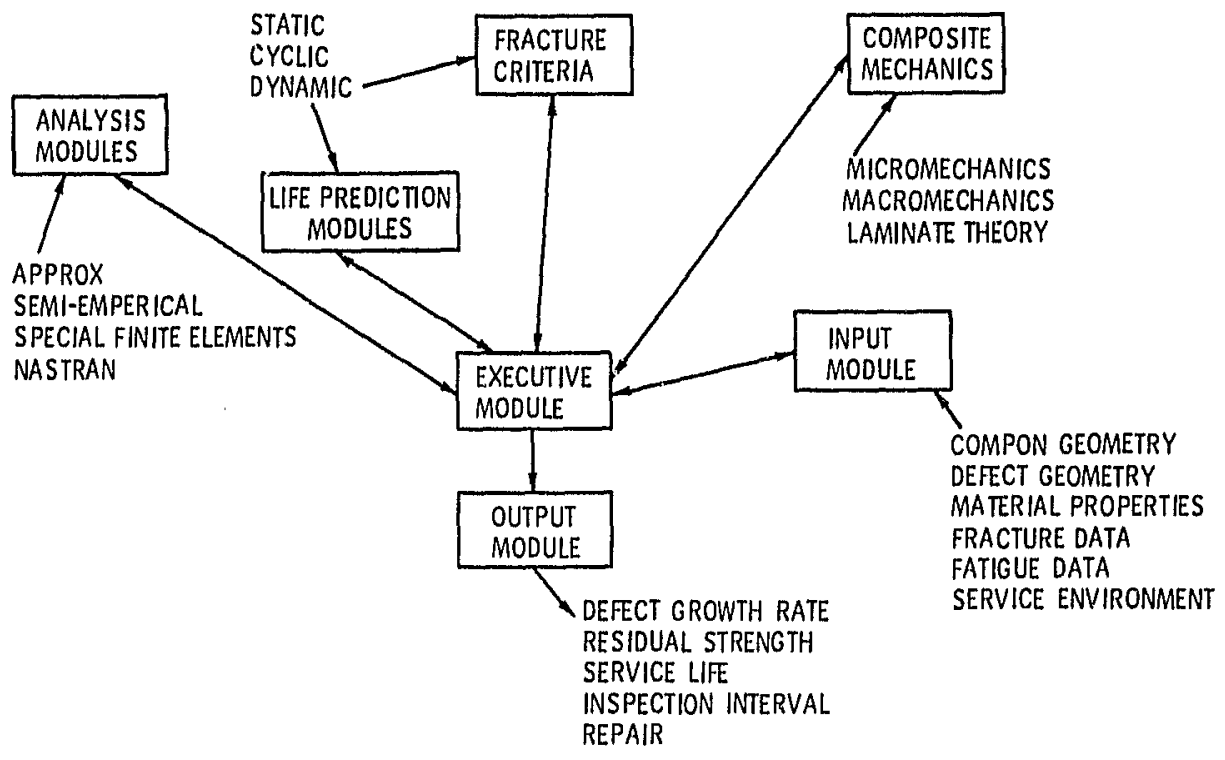

Figure 10. - CODSTRAN COmposite Durabllity STRuctural Akw.ysls. 


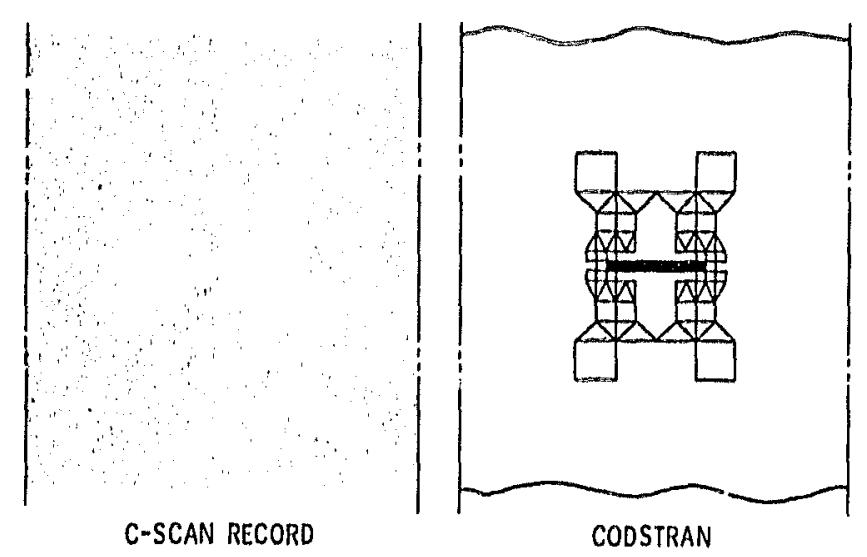

Figure 11. - $c$-scan/CODSTRAN defect yrowth comparisons, 50 percent fracture load.

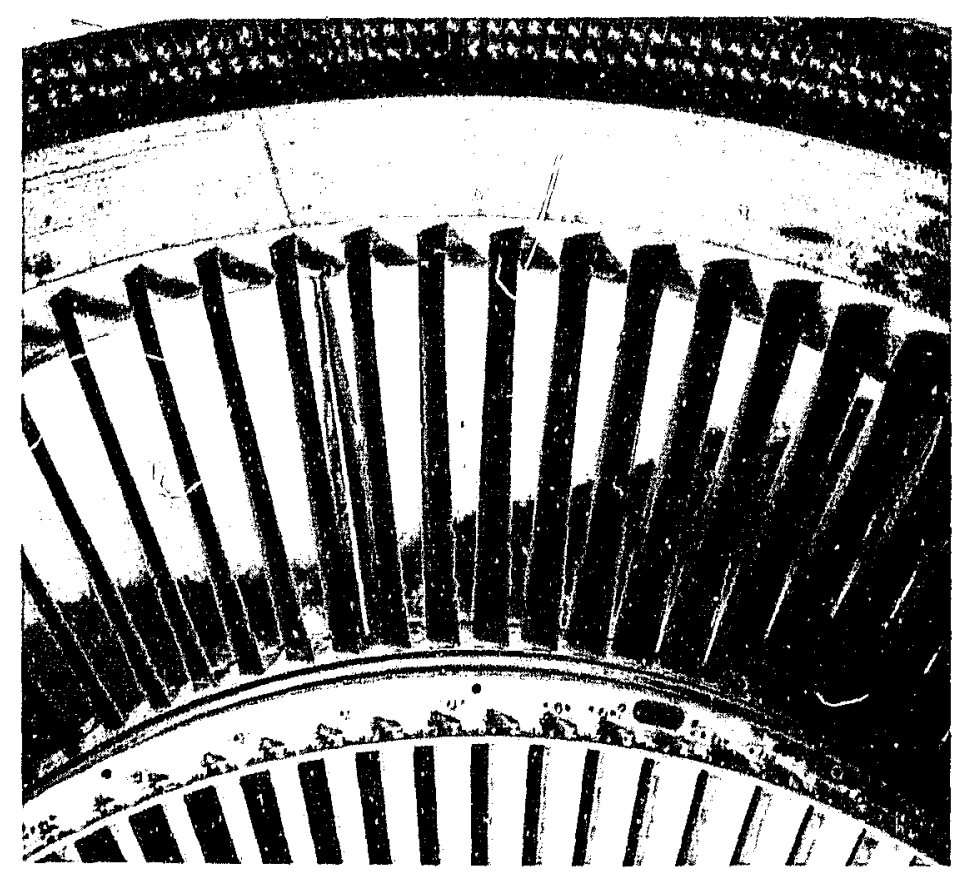

Figure 12. - Lightwelght, composite fan-exlt guide vanes for high-bypassratio lurbofan engines.

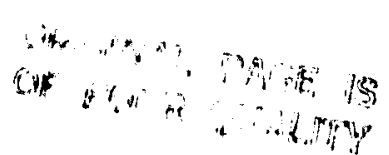




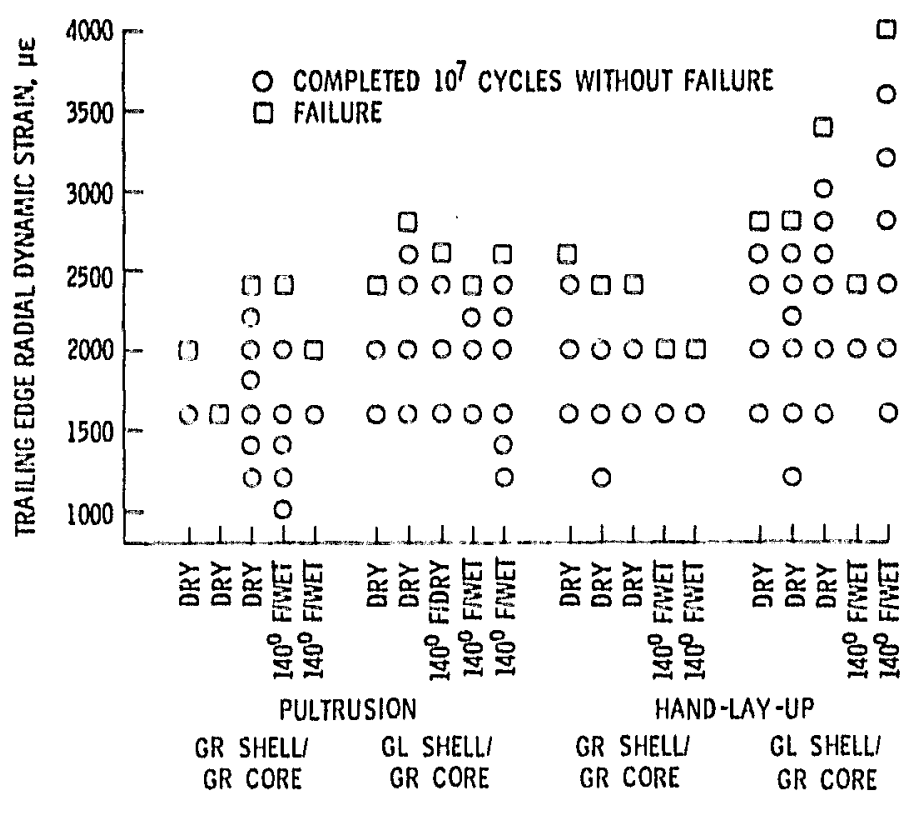

Figure 13. - Composite tan exil gulde vane fatigue test sequence. 